\title{
A new trap-jawed ant (Hymenoptera: Formicidae: Haidomyrmecini) from Canadian Late Cretaceous amber
}

\author{
Ryan C. McKellar, ${ }^{1}$ James R.N. Glasier, Michael S. Engel
}

\begin{abstract}
A new genus and species are described within the extinct tribe Haidomyrmecini, and tentatively placed within the subfamily Sphecomyrminae (Hymenoptera: Formicidae). Haidoterminus cippus new genus and species expands the distribution of the bizarre, exclusively Cretaceous, trap-jawed Haidomyrmecini beyond their previous records in mid-Cretaceous Burmese and French amber, and into Laurentia. The new material from the Grassy Lake, Alberta, Canada collecting locality also provides evidence that these highly specialised, likely arboreal, ants persisted for an additional 20 million years, reaching the Late Cretaceous. Morphological features of H. cippus, such as the presence of an elongate antennomere II (pedicel), further support the argument that Haidomyrmecini may not actually belong within the subfamily Sphecomyrminae, and may warrant recognition at the subfamily level or inclusion as a highly autapomorphic clade within another subfamily. Despite the introduction of new fossil material, and the clarity of preservation in Canadian amber, the mystery of how Haidomyrmecini fed remains unsolved.
\end{abstract}

Résumé-Nous décrivons un nouveau genre et une nouvelle espèce de la tribu fossile des Haidomyrmecini et les plaçons avec hésitation dans la sous-famille des Sphecomyrminae (Hymenoptera: Formicidae). Haidoterminus cippus nouveau genre et nouvelle espèce élargit la répartition des Haidomyrmecini à mâchoires en piège, insectes bizarres connus exclusivement du Crétacé, au-delà des récoltes signalées dans l'ambre de France et de Birmanie du Crétacé moyen jusque dans la Laurentie. Ces nouveaux spécimens provenant du site de récolte de Grassy Lake, Alberta, Canada, indiquent aussi que ces fourmis fortement spécialisées et vraisemblablement arboricoles ont persisté pendant 20 millions d'années supplémentaires pour atteindre de Crétacé supérieur. Des caractéristiques morphologiques de H. cippus, telles que la présence d'un antennomère II (pédicelle) allongé, fournissent des arguments supplémentaires à la thèse voulant que les Haidomyrmecini n'appartiennent pas vraiment à la sous-famille des Sphecomyrminae, mais qu'ils doivent être reconnus comme une sous-famille particulière ou alors être inclus comme un clade fortement autapomorphique dans une autre sous-famille. Malgré la découverte de ce nouveau matériel fossile et l'excellente qualité de sa conservation dans l'ambre canadien, le mystère du mode d'alimentation des Haidomyrmecini reste entier.

\section{Introduction}

Ants (Hymenoptera: Formicidae) are one of the most diverse and dominant insect groups in modern terrestrial settings (Hölldobler and Wilson 1990), but this was not the case in the Mesozoic. The fossil record of Formicidae is sparse within the Cretaceous, suggesting that the family

Received 2 September 2012. Accepted 21 October 2012. First published online 15 May 2013.

R.C. McKellar, ${ }^{1}$ Division of Entomology (Paleoentomology), Natural History Museum, and Department of Ecology \& Evolutionary Biology, University of Kansas, 1501 Crestline Drive - Suite 140, Lawrence, Kansas 66045, United States of America; and Department of Earth \& Atmospheric Sciences, University of Alberta, 1-26 Earth Sciences Building, Edmonton, Alberta, Canada T6G 2E3

J.R.N. Glasier, Department of Renewable Resources, University of Alberta, 814 General Services Building, Edmonton, Alberta, Canada T6G 2H1

M.S. Engel, Division of Entomology (Paleoentomology), Natural History Museum, and Department of Ecology \& Evolutionary Biology, University of Kansas, 1501 Crestline Drive - Suite 140, Lawrence, Kansas

66045, United States of America

${ }^{1}$ Corresponding author (e-mail: ryan.mckellar@ku.edu).

Subject editor: Bradley Sinclair

doi: $10.4039 /$ tce. 2013.23

http://zoobank.org/urn:lsid:zoobank.org:pub:D76EEB57-23E0-465E-B4C3-826C6762CE0A 
originated in the Early Cretaceous and only rose to a position of ecological dominance in the Eocene (Grimaldi et al. 1997; Grimaldi and Agosti 2000; Ward 2007; Perrichot et al. 2008a). Ants comprise a minor component of the assemblage found within most of the world's major Cretaceous amber deposits (Perrichot et al. 2008a), and these representatives are a mixture of extinct formicid subfamilies such as Sphecomyrminae and Brownimeciinae, found alongside less numerous representatives of the extant subfamilies Dolichoderinae and Formicinae, and possible examples of Ponerinae and Aneuretinae (Engel and Grimaldi 2005). Among the sphecomyrmines that have been reported to date, the tribe Haidomyrmecini has presented one of the most enigmatic discoveries. Members of this tribe possess distinctive, sickle-shaped mandibles that appear to have occluded against the head capsule, (swinging largely in a vertical plane) - as opposed to modern trap-jawed ants, whose mandibles swing predominantly in the horizontal plane (Barden and Grimaldi 2012).

Haidomyrmex cerberus Dlussky was the first member of Haidomyrmecini to be described, and was discovered in Early Cretaceous (Albian/ Cenomanian) Burmese amber (Dlussky 1996; Shi et al. 2012). The single, partial specimen of $H$. cerberus was later revisited and refigured in the review of Cretaceous amber Formicidae presented by Engel and Grimaldi (2005). Subsequently, Haidomyrmodes mammuthus Perrichot et al. was described from a series of three specimens, including both alate and worker females, found within Early Cretaceous (Albian-Cenomanian) amber from Charente-Maritime, France (Perrichot et al. 2008b; Perrichot et al. 2010). Most recently, Barden and Grimaldi (2012) have described two additional species from Burmese amber, Haidomyrmex scimitarus (a dealate female) and Haidomyrmex zigrasi (a worker). The new material from Late Cretaceous (Campanian) Canadian amber is only the sixth specimen known for this tribe, and is far removed from all previous records, both palaeogeographically and temporally.

The ant assemblage within Canadian amber is fairly typical of most Cretaceous ambers in terms of both relative abundance (significantly $<1 \%$ of all insect inclusions), and which subfamilies are represented within the deposit (Pike 1995; Grimaldi and Agosti 2000; Engel and Grimaldi 2005). Described species include: Sphecomyrma canadensis Wilson (Sphecomyrminae, $n=2$ ); Eotapinoma macalpini Dlussky (Dolichoderinae, $n=1$ ); Canapone dentata Dlussky (Ponerinae, $n=1)$; and Cananeuretus occidentalis Engel and Grimaldi (Aneuretinae, $n=2$ ). This places Canadian amber slightly ahead of other Cretaceous ambers in the number of subfamilies represented, but it is unclear to what extent this reflects overall diversity, or the varied habitats sampled by different amber deposits (McKellar and Engel 2012). Canadian amber provides an important glimpse into formicid evolution, because it is the last amber with a high diversity of inclusions prior to the end of the Cretaceous (Grimaldi and Engel 2005). As such, Canadian amber captures the last records of formicid tribes that apparently went extinct near the end of the Cretaceous, and provides some indication of standing diversity during the early part of the formicid radiation.

The botanical source, geological setting, and biodiversity of inclusions in Canadian amber have recently been reviewed (e.g., Pike 1995; McKellar et al. 2008; McKellar and Wolfe 2010). Canadian amber was formed $\sim 78-79$ million years ago, as resins from cupressaceous trees living along the margins of the Western Interior Seaway were trapped in nearby salt marsh or lagoonal sediments. These sediments and the resins that they hosted underwent diagenesis, and ultimately became part of the Taber Coal Zone within the Upper Cretaceous Foremost Formation. The Taber Coal Zone is exposed in a series of abandoned pit mines in the vicinity of the hamlet of Grassy Lake, in southern Alberta, Canada, and full locality details are available to researchers through the Royal Tyrrell Museum of Palaeontology. To date, all known formicids from Canadian amber have been collected from the Grassy Lake site (near Medicine Hat), not the secondary deposit of correlatable material along the shores of Cedar Lake, in western Manitoba.

\section{Materials and methods}

Specimens were prepared using established techniques for the preparation of fragile amber specimens (Nascimbene and Silverstein 2000), 
and the resulting epoxy-embedded amber pieces were slide mounted and polished to obtain thin sections. Observations were made using an Olympus (Center Valley, Pennsylvania, United States of America) SZX12 stereomicroscope, and were supplemented with compound microscopy on an Olympus BX51. Photomicrographs were prepared using a Canon (Melleville, New York, United States of America) EOS 7D camera attached to an Infinity (Boulder, Colorado, United States of America) K-2 long-distance microscope with Microptics flash lighting (a discontinued line of $6000 \mathrm{~K}$ adjustable flashes routed through fibre optic light guides). A Zeiss (Thornwood, New York, United States of America) Axio Imager A1 was used for dark field compound microscopy. The resulting image sequences were subjected to focal plane enhancement with Helicon Soft (Kharkov, Ukraine) Helicon Focus software (version 4.60). In an attempt to make this work more accessible, terminology generally follows the generalised Hymenoptera set of Goulet and Huber (1993), with clarifications for taxon-specific terms: terms unique to Formicidae stem from Hölldobler and Wilson (1990) and Bolton (1994); terms unique to Haidomyrmecini are described in Barden and Grimaldi (2012). Institutional abbreviations used herein are: UASM, University of Alberta Strickland Entomology Museum, Edmonton, Alberta, Canada.

\section{Systematic Palaeontology}

Family Formicidae Latreille, 1802

Subfamily Sphecomyrminae Wilson and Brown, 1967

\section{Comments}

Haidoterminus cippus new genus and species displays a mixture of characters that variably agree or disagree with the diagnosis for Sphecomyrminae, as defined by different authors. Under the original subfamily concept (e.g., Wilson et al. 1967; Dlussky 1975, 1983, 1987), H. cippus would be excluded due to its elongate mandible with three teeth. Grimaldi et al. (1997) considered most of the diagnostic criteria originally proposed for the subfamily to be symplesiomorphies for the Formicidae as a whole, and suggested three new synapomorphies for the tribe: a short second antennomere ("funicular article I", or "pedicel" in various Hymenoptera groups), slightly longer than wide; an elongate antennomere III (flagellar article I), at least double the length of subsequent segments; and the absence of vein $\mathrm{CuA} 1$ in the male forewing. These authors also emphasised the presence of a metapleural gland in Sphecomyrminae. Although H. cippus possesses a metapleural gland, and is the only member of Haidomyrmecini to actually possess an elongate antennomere III, its second antennomere is clearly too long to meet these updated criteria, with a length subequal to that of antennomere III.

Bolton (2003) added additional details to the subfamily diagnosis. He indicated that: the length of the scape (antennomere II) in Sphecomyrminae is $\sim 0.25$ times the combined length of the subsequent antennomeres; the eyes are positioned behind the midlength of the head; the metapleural gland is open and unobstructed laterally; the mesoscutum and mesoscutellum are separated, and propodeal lobes are not present; there are paired spurs on the mesotibia and metatibia, as well as a preapical tooth on each pretarsal claw; the petiole is short-pedunculate with a low node and a ventrally situated attachment to the gaster, which lacks a gastral constriction; the sting is present; and vein $\mathrm{Cul}$ is absent in alate individuals. Of the characters observable in $H$. cippus, all subfamily criteria (sensu Bolton 2003) are met except for the scape length, which is closer to 0.5 times the combined length of the subsequent antennomeres (a condition shared with Brownimeciinae Bolton, 2003 and other ant lineages), the position of the clypeus, which forms a raised pad situated between the antennal bases, and the presence of a single metatibial spur.

We tentatively place the new material described here within Sphecomyrminae, following the classification of Bolton (2003) and much of the work on fossil ants (Engel and Grimaldi 2005; Perrichot et al. 2008b; Barden and Grimaldi 2012). Previous authors have noted that this subfamily placement is likely unsatisfactory (e.g., Grimaldi et al. 1997; Perrichot et al. 2008b), but at present, it is the only suitable option. Large-scale reanalysis of the formicid subfamilies will be necessary to resolve the placement of Haidomyrmecini, but this is beyond the scope of the current study. 
Tribe Haidomyrmecini Bolton, 2003

\section{Type genus}

Haidomyrmex Dlussky, 1996. Other genera included, Haidomyrmodes Perrichot et al., 2008b, Haidoterminus new genus.

\section{Comments}

The diagnostic characters for this tribe that were provided by Bolton (2003) were later emended by Perrichot et al. (2008b). The Canadian amber specimen does not appear to have a slight gastral constriction (between abdominal segments 3 and 4, or gastral segments 1 and 2), but this has recently been demonstrated to be absent in two further species of Haidomyrmex (Barden and Grimaldi 2012) and was not preserved in the type specimen of $H$. cerberus (see Engel and Grimaldi 2005). Haidoterminus cippus does possess an elongate antennomere III (as opposed to an elongate segment IV in Haidomyrmex, and subequal segments in Haidomyrmodes), which appears to be the primitive condition within Sphecomyrminae, and highly variable within Haidomyrmecini. Otherwise, all diagnostic criteria for the tribe are present in H. cippus.

\section{Key to the genera and species of Haidomyrmecini}

1. Basal part of mandible short, small gap between enlarged anterior tooth and surface of face; compound eyes large, diameter $\approx 0.4$ of head length; ocelli present; no stiff setae on clypeal pad . . . . . . Haidomyrmodes mammuthus Perrichot et al., 2008b (Charentes amber, France, Late Albian-Early Cenomanian) Basal part of mandible long, large gap between elongate anterior tooth and surface of face; compound eyes small, diameter $\approx 0.2$ of head length; ocelli absent; stiff setae present on clypeal pad $\ldots \ldots \ldots \ldots \ldots$

2. Antenna with 10 flagellar articles (12 antennomeres); clypeal pad positioned largely posterior to antennal bases; one

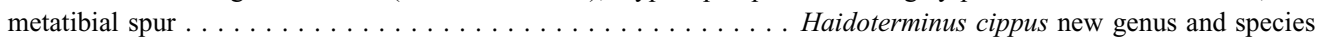

(Grassy Lake amber, Canada, Campanian) Antenna with 9 flagellar articles (11 antennomeres); clypeal pad positioned largely anterior to antennal bases; two

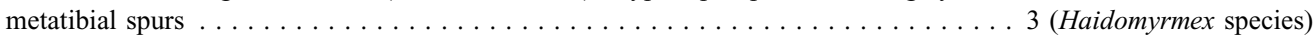

3. Mandible without basal teeth; compound eye diameter $\sim 0.2$ of head length ...... H. cerberus Dlussky, 1996 (Burmese amber, Myanmar, Albian/Cenomanian) Mandible with basal teeth; compound eye diameter more than 0.2 of head length $\ldots \ldots \ldots$

4. Propleuron forming "neck" and exposed dorsally; relatively large, total body length $\sim 7-8$ mm; maxillary palps long; vertex glabrous; mandible with multiple basal teeth . . . . . . . . . . H. scimitarus Barden and Grimaldi, 2012

(Burmese amber, Myanmar, Albian/Cenomanian) Propleuron forming "neck" and not exposed dorsally; small, total body length $\sim 3-4 \mathrm{~mm}$; maxillary palps short;

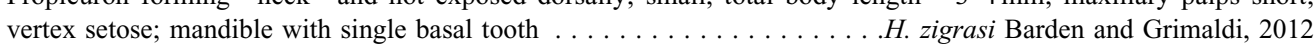

(Burmese amber, Myanmar, Albian/Cenomanian)

\section{Haidoterminus McKellar, Glasier, and Engel}

\section{Type species}

Haidoterminus cippus new species, here designated.

\section{Etymology}

The name is a combination of Haidomyrmex, the type genus of Haidomyrmecini, and terminus, Latin for "end or boundary". It refers to the position of the new genus as the last representative of its tribe within the fossil record. The name is masculine.

\section{Diagnosis and description}

Small, total body size close to $3 \mathrm{~mm}$; compound eye small and ovoid, maximum diameter $\sim 0.2-0.3$ of cephalic length; vertex bearing moderately dense coat of short, curved setae, with sporadic, long, suberect setae interspersed; ocelli absent; antenna relatively short $(0.37$ of total body length) with 12 segments (Figs. 1, 2); antennal insertion surrounded by fine carina around torulus, apparently with small frontal carina directed in transverse plane between torulus and dorsal clypeal pad (Fig. 3A-3C); scape elongate and nearly cylindrical, 0.48 of combined length of subsequent antennomeres; antennomere II markedly long, subequal to longest flagellar article; antennomere III (flagellar article I) long, nearly double length of segments IV-VIII; face with fine longitudinal rugae present in triangular patch between dorsal 
margin of oral cavity and mid-height of facial concavity; clypeal pad somewhat columnar, but with acute dorsal margin extending much farther (dorsally) than partially rounded ventral margin; pad situated almost completely posterior to antennal bases; clypeus with transverse rows of stout stiff setae or spicules, surrounded by fringe of long erect setae; scythe-shaped mandible with basal angle deep (anteroposteriorly), and bearing at least two relatively coarse basal teeth; combination of deep facial depression and elongate mandibular bases creating large gap between face and mandibles; propleurae long and slender, forming ventral half of mesosomal "neck", but not exposed dorsally; mesoscutellum separated from mesoscutum by deep, broad sulcus, which is divided by fine longitudinal carinae; propodeum nearly hemispherical, with exceedingly faint carinae or rugulae on dorsal surface, along with mid-length suberect setae in low density; procoxa elongate, slightly shorter than propleuron; clear trochanter and trochantellus present on metaleg; single metatibial spur present (clear views of the left metatibial apex from both sides and no second spur is evident); no gastral constriction present (between gastral tergites I and II, or abdominal segments III and IV).

\section{Comments}

Of the two genera previously recognised within Haidomyrmecini, $H$. cippus is most similar to Haidomyrmex. The new specimen possesses most of the diagnostic characters for Haidomyrmex as outlined by Bolton (2003) and Engel and Grimaldi (2005), but differs from this genus concept most notably in the possession of an elongate antennomere III (as opposed to an elongate segment IV in Haidomyrmex: Bolton 2003), and the single metatibial spur. The sole difference between $H$. cippus and the expanded Haidomyrmex diagnosis of Barden and Grimaldi (2012) is a smaller total body length $(3.2 \mathrm{~mm}$ in $H$. cippus), compared with the $3.5-8.0 \mathrm{~mm}$ indicated by these authors. Despite these similarities, our observations indicate that $H$. cippus is distinct: it possesses a clear trochantellus, something that is absent in Haidomyrmex (Grimaldi et al. 1997). Furthermore, Haidoterminus is unique among Haidomyrmecini in the possession of a clypeal pad largely posterior to the antennal bases, a single metatibial spur, and
12 antennomeres, compared with the 11 antennomeres present in all described Haidomyrmex and Haidomyrmodes species and castes.

Engel and Grimaldi (2005) noted many similarities between Haidomyrmex and Brownimecia clavata Grimaldi et al., 1997 (the sole representative of Brownimeciinae). Haidoterminus cippus is closely allied to Haidomyrmex, adding the possession of a proportionally elongate scape, and a pectinate metatibial spur, to the list of features shared between members of Haidomyrmecini and Brownimeciinae. Haidomyrmecini may be better placed in the latter subfamily than within Sphecomyrminae.

\section{Haidoterminus cippus McKellar, Glasier, and Engel}

Figs. 1-3

\section{Material examined}

Holotype: female, worker, UASM 332546; Late Cretaceous (Campanian) amber, Foremost Formation, Grassy Lake locality, southern Alberta, Canada. Specimen donated by Mark Elaschuk.

\section{Etymology}

The specific epithet cippus is Latin for "pillar or gravestone", and refers to the columnar appearance of the pronounced clypeal pad.

\section{Diagnosis}

See generic diagnosis and description.

\section{Description}

Total body length $\sim 3.2 \mathrm{~mm}$; cuticle with fine punctures over most body regions. Head roughly globose in shape with exception of large, protruding genae and concave clypeal region; including mandibles, head length $\sim 0.55 \mathrm{~mm}$. Vertex rounded and setose (Fig. 3A-3C); genae smooth with short, erect setae on posterior margin; occiput small and completely overhung (dorsally) by vertex. Compound eye ovoid in lateral view, small, and highly convex; ommatidia comparatively large and present in low numbers, with moderately long, erect setae scattered among ommatidia. Antenna with basal bulb and radicle exposed, radicle angled relative to scape, and positioned near posterior margin of 
Fig. 1. Haidoterminus cippus new genus and species photomicrographs, holotype, UASM 332546: (A) right lateral view; (B) left lateral view. Anterior margin of mandibles partly obscured by prominent drying line in amber; only one trigger seta arising from clypeus preserved completely, others partly preserved; specimen missing right mesotibial apex and mesotarsus, and portions of left metatarsus; right metaleg too poorly preserved for detailed observation; sting truncated by edge of amber piece; gaster partly decayed, perforated on right side, and largely ruptured on left side.

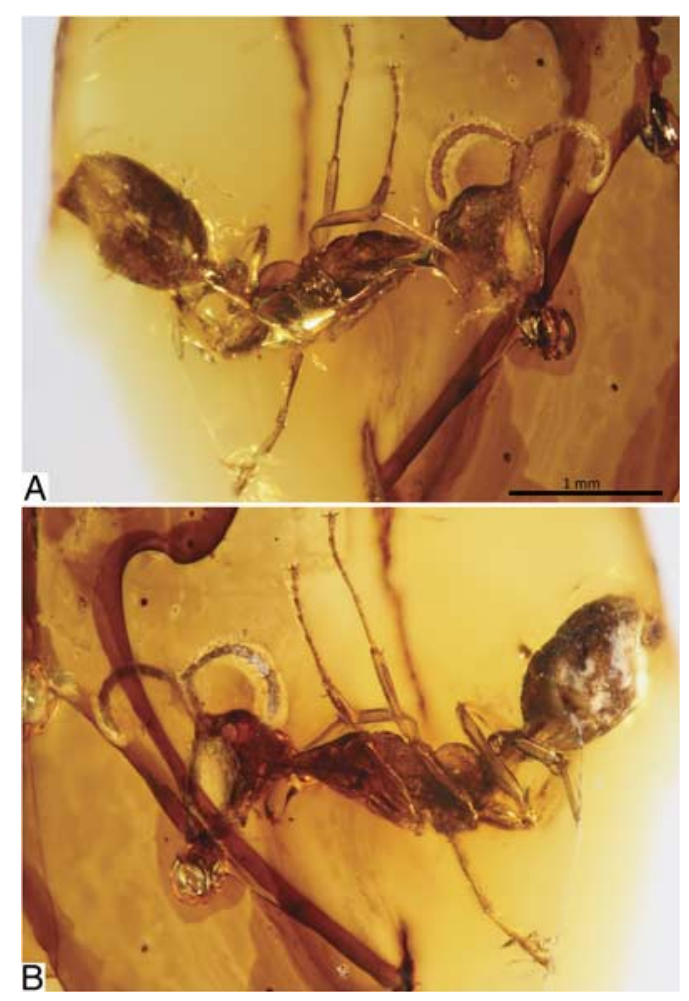

scape; scape and antennomere II with coat of moderately long, inclined setae, and with few suberect setae along posterior margin of apex (Fig. 3C); flagellar articles all bearing short, inclined setae in moderate density; flagellar article $\mathrm{X}$ with rounded apex. Face with concave anterior surface; oral margin adjacent to labrum rimmed by four or more long, inclined setae, with at least two additional long setae near mid-height of facial rugosity; clypeal setation (Figs. 2A, 3C, consisting of transverse rows of stout, dagger-shaped, stiff setae or spicules, concentrated within ventral half of pad and becoming progressively longer towards ventral margin of pad; clypeal spicules surrounded by much more elongate, erect setae in large numbers adjacent to ventral margin of pad, with few elongate, curved setae forming scattered fringe along dorsal surface of clypeal pad; pair of exceptionally long trigger setae originating from lateroventral surfaces of clypeal pad and extending to reach near oral cavity (only one seta preserved fully). Mandibles with long (exsagittally) and narrow (dorsoventrally) bases terminating in broad (exsagittally) basal angle; enlarged anterior tooth blade-like and smooth, gradually tapering to acute point near contact with clypeal pad; anterior tooth with numerous short setae apparently recumbent upon inner surface, and row of six or more stiff setae along subapical portion of anterior margin. Maxillary palp large, with four palpomeres, with coarse stiff setae erect upon anterior surface of each palpomere (Fig. 3B). Labial palp diminutive, apparently with two or more short segments, each bearing fine, stiff setae.

Mesosoma or alitrunk elongate ( 0.39 of total body length) and shallow, with pronounced "neck" comprised largely propleurae, and strong constriction just posterior to pronotum; pronotum elongate and narrow, extending posteriorly well beyond procoxal bases, with posterior margin incised by mesopleuron; pronotum with weak dorsal convexity, and bearing short, inclined setae in low density; promesonotal suture deeply impressed and apparently flexible; mesoscutum displaying fine longitudinal carinae along lateral margin of dorsal surface, and also with long, suberect setae; mesoscutellum rounded and dorsally prominent, but short (exsagittally), $\sim 0.6$ of mesoscutal length; rounded lip around posterior margin of mesoscutellum may represent metanotum; metanotal sulcus well impressed; propodeal declivity steep; metapleural gland opening (Fig. 2B) present in posteroventral corner of propodeum and opening laterally; propodeal spiracle positioned within anterior half and near mid-height of propodeal hemisphere. Legs elongate and gracile (near 0.6 of total body length); procoxa with thin, elongate setae suberect on ventral surface near apex; profemur slightly swollen within its basal half, with long, thin setae predominantly on dorsal surface, 
Fig. 2. Haidoterminus cippus new genus and species habitus diagrams, holotype, UASM 332546: (A) right lateral habitus; (B) left lateral habitus. Preservational conditions explained in Fig. 1, right metatibia and metatarsus not illustrated due to poor preservation, grey areas denote bubbles, and dashed lines denote truncated appendages; MGO, metapleural gland opening; PES, petiolar spiracle; PRS, propodeal spiracle.

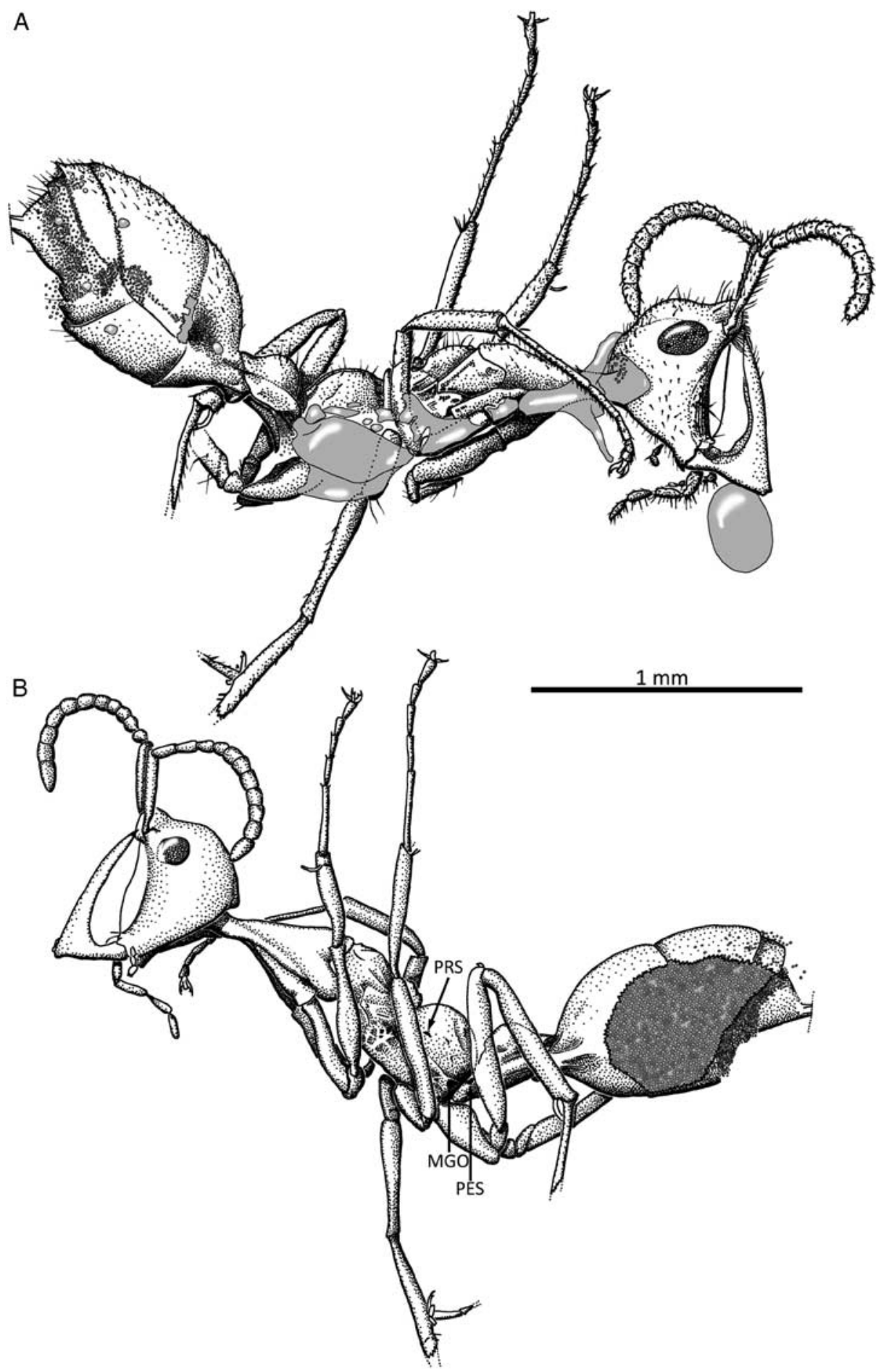


Fig. 3. Haidoterminus cippus new genus and species photomicrographs, holotype, UASM 332546: (A) detailed left lateral view of head (b.f.); (B) detailed left lateral view of head (d.f.); (C) expanded view of clypeal pad setation and scape, left lateral view (d.f.); (D) protibial apex, and protarsus (b.f.); (E) apex of gaster, bright line extending from lower left corner of image to middle of upper margin is edge of amber piece, arrows indicate dorsal and ventral margins of truncated sting. Scale bars $0.25 \mathrm{~mm}$.
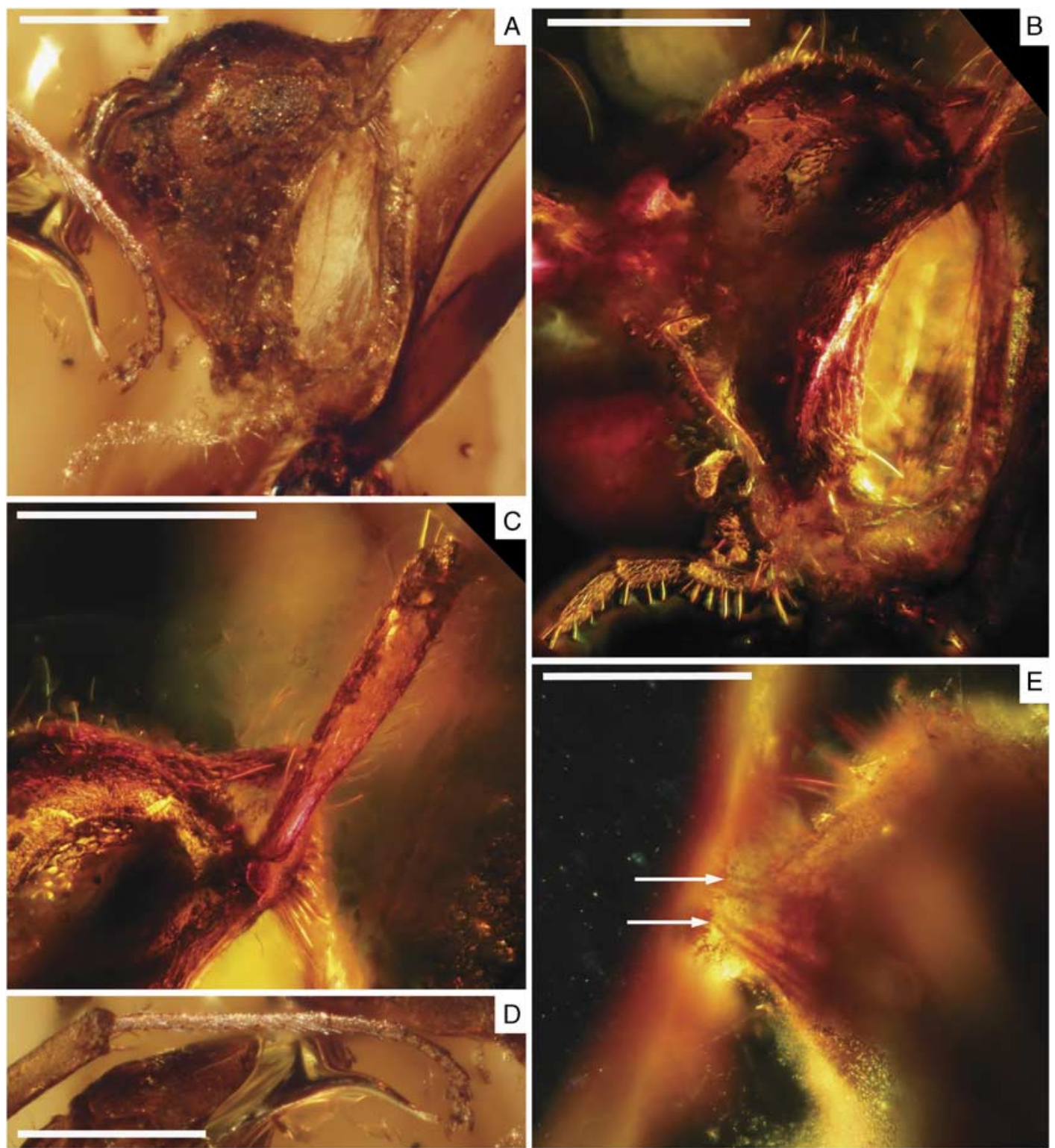

and accompanied by distinct trochanter and trochantellus basally (orientation renders trochantellus less visible than in metaleg, while trochantellus cannot be clearly distinguished in either mesoleg); all tibiae with slight apical expansion; anterior protibial spur (calcar) large, gently curved and simple, length 1.5 times apical width of protibia; posterior protibial spur diminutive and straight, length subequal to apical width of protibia; protibial setation comprised 
short, coarse setae inclined on most surfaces, but more dense on apical and dorsal surfaces; all protarsomeres with short, coarse, inclined setae concentrated on ventral surface, probasitarsomere with setae slightly more elongate; protarsomeres with apical row of four or more short spicules that are difficult to differentiate from their setae; pretarsal claws with one subapical tooth perpendicular to long axis; arolium well developed and surrounded by approximately four long, thin setae; mesocoxa separated from procoxa by expansive mesopleuron, and bearing single row of fine, elongate setae (as long as coxal width); mesofemur similar to profemur, but more gracile; mesotibia with two relatively short apical spurs, both spurs subequal to mesotibial apical width, and surrounded by approximately five long, stiff setae; mesobasitarsus less setiferous than probasitarsus, with pair of spicules or stiff setae adjacent to base, plus 10 or more in apical half, concentrated primarily on apical part of ventral surface; metacoxa long, approximately one-third of metafemoral length; metafemur robust, with many short, fine setae inclined on dorsal surface; metatibia comparable in thickness to metafemur throughout most of its length; sole metatibial spur sinuous and long, $\approx 1.25$ times apical width of metatibia, bearing numerous fine setae along its inner margin, and with row of fine, erect, stiff setae adjacent to spur insertion; metabasitarsomere with row of inclined fine setae forming comb beneath contact with metatibial spur, comb extending to reach double the spur length, with individual setae gradually diminishing in length apically; apical to comb, stiff setae, or spicules present in low density on ventral surface of metabasitarsomere; apex of left metabasitarsus not preserved, and right leg too poorly preserved to permit observation of metatarsus.

Metasoma with petiole short-pedunculate with low, hemispherical node, and apparently with prominent lateral ridges extending from ventral margin of node (these ridges may be due to preservational distortion - petiolar sternite appears to have separated and partly deformed during early stages of preservation), as well as shelf dorsal to helcium; peduncle depressed, with propodeal articulation low (ventrally); propodeal spiracle exposed along lateral margin of peduncle, just posterior to propodeal articulation
(Fig. 2B); petiolar length 0.13 of total body length; petiolar setation consisting of moderately long, inclined setae in low numbers, with sporadic, long, suberect setae interspersed; gaster (metasoma excluding petiole) 0.30 of total body length; gastral segmentation difficult to discern due to partial decay of gaster (on left side with small perforation on right side) and bubble-clouding (on right side, particularly near pygidium); gastral tergite I and II apparently 0.36 and 0.45 of total gastral length, respectively, while tergites III, IV, and V (pygidium) are largely concealed by preceding tergites; tergites with pervasive dense coat of short, inclined, curved setae, with sporadic long, fine setae suberect on tergite II and subsequent tergites, and with suberect setae becoming more numerous and gently curved on tergites III-V; sternites with translucent preservation, rendering observation difficult, apparently only bearing sparse, long, thin, gently curved setae near mid-length of gaster and on pygidium; pygidium protruding and highly setose; sting robust and only preserved basally, with remainder truncated by contact with edge of amber piece.

Measurements (in $\mathrm{mm}$ ): total body length (outstretched) 3.19; head (posterior margin of head to anterior margin of clypeus) 0.55 ; mesosoma (alitrunk) 1.23; petiole 0.43 ; gaster 0.98 ; total antenna 1.18 ; scape 0.38 ; antennomere II) 0.10 ; flagellar articles I-X $(0.10,0.06,0.05,0.05,0.05$, $0.06,0.07,0.07,0.07,0.12$ ); mandible (along anterior edge) 0.59 ; procoxa 0.40 , mesocoxa 0.27 , metacoxa 0.34 , profemur 0.58 , mesofemur 0.54 , metafemur 0.67 , protibia 0.39 , mesotibia 0.55 , metatibia 0.66 , protarsomeres I-V $(0.29,0.11,0.08$, $0.07,0.07)$, mesotarsomeres $\mathrm{I}-\mathrm{V}(0.31,0.13,0.12$, $0.10,0.11)$, metatarsomeres $\mathrm{I}-\mathrm{V}(0.40$ ?, possibly missing apex).

\section{Discussion}

With so few species known in Haidomyrmecini, it is not difficult to distinguish $H$. cippus from the remainder of its tribe. Aside from possessing an additional flagellar article, $H$. cippus is unique in that its clypeal pad extends posterior to the antennal bases, and that it possesses a single metatibial spur. The new species shows many morphological similarities to Haidomyrmex species, but does not possess a suite of characters 
that would indicate a close relationship to any particular member of this genus.

Haidoterminus cippus is an interesting discovery because it extends the temporal range of the Haidomyrmecini by approximately 20 million years, into the Late Cretaceous (Goodwin and Deino 1989; Eberth and Deino 1992; Shi et al. 2012). It also expands the palaeogeographic range of this tribe into Laurentia (present-day North America). This suggests that despite specialised morphology, the group was relatively widespread in the Cretaceous, and successful in a range of habitats. The three amber deposits currently known to contain haidomyrmecines were formed within markedly different biomes, meaning that the tribe must have been able to survive in a wide range of conditions.

Charentes amber (France) has been suggested to be the product of conifers belonging to either Araucariaceae or Cheirolepidiaceae, that lived in marginal marine settings within a warm temperate or subtropical forest (Perrichot et al. 2010, and references therein). Charentes amber also appears to be biased toward capturing arboreal and forest floor taxa (Perrichot 2004; Perrichot et al. 2007; Schmidt et al. 2010), and was deposited at a palaeolatitude of $\sim 32^{\circ} \mathrm{N}$ (MartínezDelclòs et al. 2004). Burmese amber is thought to be the product of Araucariaceae or Cupressaceae (likely Metasequoia Miki; Cupressaceae) living under tropical conditions at a palaeolatitude of $\sim 5^{\circ} \mathrm{N}$ (Grimaldi et al. 2002; Martínez-Delclòs et al. 2004; Poinar et al. 2007; Ross et al. 2010). The most recent work on Canadian amber has indicated that it was produced by cupressaceous trees (likely Parataxodium Arnold and Lowther; Cupressaceae), living under warm temperate conditions within marginal marine settings along the coast of a shallow inland sea at $\sim 57^{\circ} \mathrm{N}$ paleolatitude (Martínez-Delclòs et al. 2004; McKellar et al. 2008; McKellar and Wolfe 2010). Together, these occurrences extend from tropical to warm temperate settings, and encompass disparate forest types, suggesting a broad palaeo-distribution for the Haidomyrmecini.

Given the latitudinal range and variety of forest types that have been encompassed by the current records of Haidomyrmecini, future work is likely to recover this tribe within other major Cretaceous amber deposits that were produced at comparable paleolatitudes, or had opportunity for faunal interchange (e.g., Siberian amber, Spanish amber, New Jersey amber, and perhaps Lebanese amber). Although ants are rarely encountered as inclusions within Cretaceous amber, almost all of the amber deposits with an appreciable number of ants recovered are now known to contain Haidomyrmecini. The one exception is New Jersey amber, with eight fossil ants reported to date, and no reports of haidomyrmecines (Grimaldi et al. 2000; Perrichot et al. 2008a). This may indicate that the group was not present on the eastern side of the Western Interior Seaway, or it may also be an artifact of the number of inclusions that are known from each deposit. The arboreal adaptations of ants within this tribe (Engel and Grimaldi 2005) suggest that they lived in close association with trees, so their representation in the amber record is almost certain to improve with the study of additional material.

One problem that persists with this tribe is our inability to explain how they could have fed. The enlarged mandible has been found in workers, as well as alate and dealate females (Perrichot et al. 2008b; Barden and Grimaldi 2012). This eliminates the possibility that the mandible is restricted to specialised, defensive workers that may have been fed by trophallaxis. Barden and Grimaldi (2012) have discussed the mechanics of the enlarged mandible within Haidomyrmex in detail. Their key findings suggest that the mandibles swung obliquely or vertically, allowing the pointed tips of the elongate anterior teeth to pin prey against the spiculose clypeal pad. In this configuration, the extremely elongate setae on either side of the clypeal pad would have acted as trigger setae for the mandibles, while the facial concavity and wide mandibular gape would have accommodated large prey items for stinging - it is unclear if the basal teeth would have been used for mastication, fine manipulation within the colony, or were simply coaptive structures (Barden and Grimaldi 2012).

The new Haidoterminus specimen presents a fairly clear view of the mandibles, but provides little indication of their use after prey capture. Barden and Grimaldi (2012) speculated that the mandibles funnelled prey haemolymph to the oral cavity. In $H$. cippus, the cuticle of the mandible is somewhat translucent, but no grooves or other structures to facilitate transport of fluids from the apices are present. There are a series of vertical 
rugae on the lower half of the facial concavity, but it is unclear whether these would have directed fluid to the mouth, strengthened the cuticle in this region, or were merely ornamental. The basal teeth from the right mandible appear to overlap the left mandible in $H$. cippus, which would suggest that these are not coaptive structures, and that the mandibles moved independently from one another. If the mandibles were swung obliquely, the gape created near the basal teeth would likely be sufficient for mastication. Coupled with long palps (and perhaps unobserved long glossae), this suggests that food manipulation may not have been a significant issue. Additionally, modern genera, such as Amblyopone Erichson, 1842, Leptanilla Emery, 1870, and Messor Forel, 1890 use larvae as food processors and gain food from larval haemolymph or regurgitated liquid (Hölldobler and Wilson 1990). If larvae were actively involved in food processing, significant amounts of mastication may not have been necessary for haidomyrmecines.

Compared with all described haidomyrmecines, H. cippus appears to have coarser basal teeth, a slightly wider gap between the mandibles and the facial surface, a deeper pocket between the basal teeth and the oral cavity, and more robust maxillary palps. It is possible that the maxillae or glossa played a more prominent role in transporting food from the mandible to the oral cavity, but without being able to observe these features directly, both this and suggestions of larval food processing are as speculative as fluid transport down the anterior tooth of the mandible. Regardless of how the mouthparts functioned, $H$. cippus demonstrates that the unique mandibular adaptations of Haidomyrmecini were successful for at least 20 million years, and were even accentuated in the last known exemplar of the tribe.

\section{Acknowledgements}

The authors thank Mark Elaschuk for donating the amber specimen, and Danny Shpeley and Felix Sperling for their assistance with the UASM collections. Subject Editor Bradley Sinclair and two anonymous reviewers provided comments that improved this work, which are greatly appreciated. Partial support was provided by United States National Science Foundation grants EF-0341724 and DEB-0542909 (both to M.S. Engel). The participation of R.C.M. was supported by a Natural Sciences and Engineering Research Council of Canada (NSERC) Postdoctoral Fellowship, as well as NSERC Discovery grants issued to B.D.E. Chatterton and A.P. Wolfe, University of Alberta. This is a contribution of the Division of Entomology, University of Kansas Natural History Museum.

\section{References}

Barden, P. and Grimaldi, D. 2012. Rediscovery of the bizarre Cretaceous ant Haidomyrmex Dlussky (Hymenoptera: Formicidae), with two new species. American Museum Novitates, 3755: $1-16$.

Bolton, B. 1994. Identification guide to the ant genera of the world. Harvard University Press, Cambridge, Massachusetts, United States of America.

Bolton, B. 2003. Synopsis and classification of Formicidae. Memoirs of the American Entomological Institute, 71: 1-370.

Dlussky, G.M. 1975. Superfamily Formicoidea Latreille, 1802. Family Formicidae Latreille, 1802. In Hymenoptera Apocrita of the Mesozoic. Edited by A.P. Rasnitsyn. Transactions of the Paleontological Institute, Academy of Sciences of the Union of Soviet Socialist Republics, Nauka Publishing House, Moscow, 147: 114-122. [In Russian].

Dlussky, G.M. 1983. A new family of Upper Cretaceous Hymenoptera: an "intermediate link" between the ants and the scolioids. Paleontologicheskii Zhurnal, 3: 65-78. [In Russian, English translation in 1984, Paleontological Journal, 17: 63-76].

Dlussky, G.M. 1987. New Formicoidea (Hymenoptera) of the Upper Cretaceous. Paleontologicheskii Zhurnal, 1: 131-135. [In Russian, English translation in 1988, Paleontological Journal, 21: 146-150].

Dlussky, G.M. 1996. Ants (Hymenoptera: Formicidae) from Burmese amber. Paleontological Journal, 30: 449-454.

Eberth, D.A. and Deino, A.L. 1992. A geochronology of the nonmarine Judith River Formation of southern Alberta. In Mesozoic of the Western Interior: Abstracts for the Society of Economic Paleontologists and Mineralogists Theme Meeting, Fort Collins, Colorado. Society for Sedimentary Geology, Tulsa, Oklahoma, United States of America. Pp. 24-25.

Emery, C. 1870. Studi mirmecologici. Bullettino della Società Entomologica Italiana, 2: 193-201.

Engel, M.S. and Grimaldi, D.A. 2005. Primitive new ants in Cretaceous amber from Myanmar, New Jersey and Canada (Hymenoptera: Formicidae). American Museum Novitates, 3485: 1-23.

Erichson, W.F. 1842. Beitrag zur Insecten-Fauna von Vandiemensland, mit besonderer Berücksichtigung der geographischen Verbreitung der Insecten. Archiv für Naturgeschichte, 8: 83-287. 
Forel, A. 1890. Fourmis de Tunisie et de l'Algérie orientale. Annales de la Société Entomologique de Belgique, 34: 61-76.

Goodwin, M.B. and Deino, A.L. 1989. The first radiometric ages from the Judith River Formation (Upper Cretaceous), Hill County, Montana. Canadian Journal of Earth Sciences, 26: 1384-1391.

Goulet, H. and Huber, J.T. 1993. Hymenoptera of the world: an identification guide to families. Research Branch Agriculture Canada, Ottawa, Ontario, Canada.

Grimaldi, D. and Agosti, D. 2000. A formicine in New Jersey Cretaceous amber (Hymenoptera: Formicidae) and early evolution of the ants. Proceedings of the National Academy of Sciences, 97: 13678-13683.

Grimaldi, D.A. Agosti, D., and Carpenter, J.M. 1997. New and rediscovered primitive ants (Hymenoptera: Formicidae) in Cretaceous amber from New Jersey, and their phylogenetics relationships. American Museum Novitates, 3208: 1-43.

Grimaldi, D.A. and Engel, M.S. 2005. Evolution of the insects. Cambridge University Press, New York, United States of America.

Grimaldi, D., Engel, M.S., and Nascimbene, P. 2002. Fossiliferous Cretaceous amber from Myanmar (Burma): its rediscovery, biotic diversity, and paleontological significance. American Museum Novitates, 3361: 1-72.

Grimaldi, D.A., Shedrinsky, A., and Wampler, T.P. 2000. A remarkable deposit of fossiliferous amber from the Upper Cretaceous (Turonian) of New Jersey. In Studies on fossils in amber, with particular reference to the Cretaceous of New Jersey. Edited by D.A. Grimaldi. Backhuys Publishers, Leiden, The Netherlands. Pp. 1-76.

Hölldobler, B. and Wilson, E.O. 1990. The ants. Harvard University Press, Cambridge, Massachusetts, United States of America.

Martínez-Delclòs, X., Briggs, D.E.G., and Peñalver, E. 2004. Taphonomy of insects in carbonates and amber. Palaeogeography, Palaeoclimatology, Palaeoecology, 203: 19-64.

McKellar, R.C., and Engel, M.S. 2012. Hymenoptera in Canadian Cretaceous amber (Insecta). Cretaceous Research, 35: 258-279.

McKellar, R.C. and Wolfe, A.P. 2010. Canadian amber. In Biodiversity of fossils in amber from the major world deposits. Edited by D. Penney. Siri Scientific Press, Manchester, United Kingdom. Pp. 149-166.

McKellar, R.C. Wolfe, A.P., Tappert, R., and Muehlenbachs, K. 2008. Correlation between Grassy Lake and Cedar Lake ambers using infrared spectroscopy, stable isotopes, and palaeoentomology. Canadian Journal of Earth Sciences, 45: 1061-1082.
Nascimbene, P. and Silverstein, H. 2000. The preparation of fragile Cretaceous ambers for conservation and study of organismal inclusions. In Studies on fossils in amber, with particular reference to the Cretaceous of New Jersey. Edited by D.A. Grimaldi. Backhuys Publishers, Leiden, The Netherlands. Pp. 93-102.

Perrichot, V. 2004. Early Cretaceous amber from south-western France: insight into the Mesozoic litter fauna. Geologica Acta, 2: 9-22.

Perrichot, V., Lacau, S., Néraudeau, D., and Nel, A. 2008a. Fossil evidence for the early ant evolution. Naturwissenschaften, 95: 85-90.

Perrichot, V., Nel, A., Néraudeau, D., Lacau, S., and Guyot, T. 2008b. New fossil ants in French Cretaceous amber (Hymenoptera: Formicidae). Naturwissenschaften, 95: 91-97.

Perrichot, V., Néraudeau, D., Nel, A., and De Ploëg, G. 2007. A reassessment of the Cretaceous amber deposits from France and their palaeontological significance. African Invertebrates, 48: 213-227.

Perrichot, V., Néraudeau, D., and Tafforeau, P. 2010. Charentese amber. In Biodiversity of fossils in amber from the major world deposits. Edited by D. Penney. Siri Scientific Press, Manchester, United Kingdom. Pp. 192-207.

Pike, E.M. 1995. Amber taphonomy and the Grassy Lake, Alberta, amber fauna. Ph.D. thesis. Department of Biological Sciences, University of Calgary, Calgary, Alberta, Canada.

Poinar, G.O. Jr, Lambert, J.B., and Wu, Y. 2007. Araucarian source of fossiliferous Burmese amber: spectroscopic and anatomical evidence. Journal of the Botanical Research Institute Texas, 1: 449-455.

Ross, A., Mellish, C., York, P., and Crighton, B. 2010. Burmese amber. In Biodiversity of fossils in amber from the major world deposits. Edited by D. Penney. Siri Scientific Press, Manchester, United Kingdom. Pp. 208-235.

Schmidt, A.R., Girard, V., Perrichot, V., and Schönborn, W. 2010. Testate amoebae from a Cretaceous forest floor microbiocoenosis of France. Journal of Eukaryotic Microbiology, 57: 245-248.

Shi, G., Grimaldi, D.A., Harlow, G.E., Wang, J., Wang, J., Yang, M., et al. 2012. Age constraint on Burmese amber based on U-Pb dating of zircons. Cretaceous Research, 37: 155-163.

Ward, P.S. 2007. Phylogeny, classification, and species-level taxonomy of ants (Hymenoptera: Formicidae). Zootaxa, 1668: 549-563.

Wilson, E.O., Carpenter, F.M., and Brown, W.L. Jr 1967. The first Mesozoic ants, with the description of a new subfamily. Psyche, 74: 1-19. 